\title{
EFFECT OF LOW-TEMPERATURE THERMAL-ALKALINE PRETREATMENT WITH ALKYL POLYGLUCOSIDES (APGS) FOR LOW-ORGANIC-CONTENT SLUDGE ON ANAEROBIC DIGESTION
}

\author{
LIU, X. ${ }^{1,2}-$ ZHANG, C. ${ }^{1,2^{*}}-$ YU, Z. ${ }^{1,2}$ \\ ${ }^{\text {I} C o l l e g e ~ o f ~ E n v i r o n m e n t a l ~ S c i e n c e ~ a n d ~ E n g i n e e r i n g, ~ H u n a n ~ U n i v e r s i t y, ~ C h a n g s h a ~ 410082, ~}$ \\ China
}

${ }^{2}$ Key Laboratory of Environmental Biology and Pollution Control (Hunan University), Ministry of Education, Changsha 410082, China

*Corresponding author

e-mail: zhangchang@hnu.edu.cn; phone/fax: +86-731-8882-2312

(Received $6^{\text {th }}$ Mar 2019; accepted $3^{\text {rd }}$ May 2019)

\begin{abstract}
Low-temperature thermo-alkaline pretreatment with alkyl polyglucosides (APGs) was employed for improving the utilization of low-organic-content sludge in anaerobic digestion (AD). An orthogonal experiment $\left(\mathrm{L}_{9}\left(3^{4}\right)\right)$ was designed to estimate the influence of four factors on pretreatment, and the order determined by significance level was: $\mathrm{pH}>$ temperature $>$ APG dosage $>$ time. Under the conditions of $\mathrm{pH} 11,60^{\circ} \mathrm{C}$, and $60 \mathrm{~min}$, the content of organic matter dissolved from sludge increased as the APG dosage increased to $18 \mathrm{~g} / \mathrm{L}$. When fermenting at a dosage above its critical micelle concentration (CMC), however, APG inhibited aerogenesis due to the adverse impact on methanogen activity. Thus, the optimal APG dosage was fixed at $3.0 \mathrm{~g} / \mathrm{L}$. After 35 days of mesophilic AD, the biogas volume, the methane volume fraction, and the organics utilization rate reached their respective peaks. The methane volume fraction (45.8\%) was lower than normal biogas (at least 53\%), so further evaluation is needed.

Keywords: surfactant, CMC, mesophilic, methanogenesis, orthogonal experiment
\end{abstract}

\section{Introduction}

The large amount of sludge generated by wastewater treatment plants (WWTPs) has been a great challenge and has raised significant concerns in China (Yang et al., 2015). Disposal methods, including sanitary landfill, land application, and incineration, are the main final destinations of sludge after treatment (Murakami et al., 2009; Song and Lee, 2010; Hale et al., 2012). Processes such as thickening, conditioning, dewatering, stabilization, and drying are commonly employed as sludge treatment methods (Yang et al., 2015). Stabilization, a well-developed approach, is an important way to reduce the environmental risks of sewage sludge. In particular, anaerobic and aerobic digestion are the most common stabilization methods, and they are usually applied in cases of small WWTPs, although the majority of produced sludge is treated anaerobically (Kelessidis and Stasinakis, 2012).

Anaerobic digestion (AD) is a complex process which is generally considered to have a rate limited by the hydrolysis of sludge (Appels et al., 2008). Therefore, pretreatments facilitating sludge hydrolysis enhance the efficiency of AD. Generally speaking, pretreatment methods include biological, thermal, mechanical (ultrasonic treatment, lysis-centrifugation, liquid shear, and grinding), and chemical (oxidation and alkalization) (Carrere et al., 2010) treatments, among which thermal treatment has been paid much attention. Thermal pretreatment can be mainly classified into two categories 
based on the temperature applied, i.e., pretreatment higher than $100{ }^{\circ} \mathrm{C}$ (need a highpressure installation) (Bougrier et al., 2008; Ennouri et al., 2016; Jae et al., 2018) and pretreatment lower than $100^{\circ} \mathrm{C}$ (under atmospheric pressure) (Appels et al., 2010; Fernández-Marchante, 2018). However, treatment in a mild temperature is often combined with a chemical method (Mendez et al., 2013), most commonly with an alkali. Some researchers (Kim et al., 2015; Zhang et al., 2015; Li et al., 2016; Du et al., 2019) have concluded that a low-temperature thermo-alkali pretreatment significantly enhances the efficiency of AD.

From studies on sludge dewatering, it was found that surfactants were highly effective in releasing extracellular polymeric substances (EPSs) from sludge (Wang et al., 2014; Liu et al., 2019). EPSs consist of high-molecular-weight secretions from microorganisms, and products of cellular lysis and macromolecule hydrolysis. A higher EPS content in sludge results in greater sludge stability (Sheng et al., 2010), so the release of EPSs from cells can facilitate the dissolution of organics, thus making a positive contribution to the hydrolysis of sludge. In short, surfactants can be chosen for sludge pretreatment (Guan et al., 2017), but their environmental friendliness must be taken into consideration.

Alkyl polyglucoside (APG) is a nonionic surfactant synthesized from renewable raw materials, and it has excellent ecotoxicological profiles, so it is readily biodegradable (Geetha and Tyagi, 2012). Luo et al. (2015) reported that adding APG to an anaerobic treatment system of waste activated sludge (WAS) improved the production of shortchain fatty acids remarkably. However, so far, no one has tried to pretreat sludge with APG before AD.

WAS with comparatively low organic content has not been qualified for AD. This study, therefore, explored the effect of low-temperature thermo-alkaline pretreatment, optimized by APG dosing of low-organic-content sludge, on AD. An orthogonal experiment was firstly designed to estimate the effects of $\mathrm{pH}$, temperature, APG dosage, and time on the pretreatment, and single factor experiments were also conducted to meet the shortcomings of the orthogonal experiment. More importantly, the role of APG dosage in $\mathrm{AD}$ was investigated by a series of fermentation experiments.

\section{Materials and methods}

\section{Test materials}

\section{Waste activated sludge}

The sludge used in this study was collected from Kaifu Wastewater Treatment Plant (Changsha, China) through a Modified Sequencing Batch Reactor (MSBR). It was dewatered by belt filter press in the plant, and it was then stored in a plastic hermetic bag at $4{ }^{\circ} \mathrm{C}$ in the laboratory. The moisture content of the sludge was $81.3 \pm 0.05 \%$.

Before each experiment, the dewatered sludge was diluted with deionized water into approximate $15 \mathrm{~g} / \mathrm{L}$ (total solids), and the ratio of volatile solids (VS) to total solids (TS) was $51.32 \pm 0.10 \%$, which is comparatively low (VS/TS of WAS for AD in the literature was generally above $70 \%$ ). The main characteristics of the sludge solution were total chemical oxygen demand $(\mathrm{TCOD})=6976.8 \pm 77.5 \mathrm{mg} / \mathrm{L}$, soluble chemical oxygen demand $(\mathrm{SCOD})=85.3 \pm 7.7 \mathrm{mg} / \mathrm{L}$, soluble total organic carbon $(\mathrm{STOC})=60.45 \pm 5.38 \mathrm{mg} / \mathrm{L}, \quad$ soluble total phosphorus (soluble $\mathrm{TP})=10.18 \pm 0.20 \mathrm{mg} / \mathrm{L}, \mathrm{pH}=6.96 \pm 0.01$. 


\section{Inocula}

For the anaerobic digestion tests, the sludge solution was anaerobically cultivated at $37^{\circ} \mathrm{C}$ for 3 days in a constant-temperature incubator in order to activate the anaerobe, and to prepare for the inocula (it is feasible to use raw WAS as inocula, as shown in the literature; Nguyen et al., 2014). Its main characteristics were TCOD = $6821.8 \pm 155.0 \mathrm{mg} / \mathrm{L}, \mathrm{SCOD}=100.8 \pm 23.3 \mathrm{mg} / \mathrm{L}, \mathrm{STOC}=66.45 \pm 3.62 \mathrm{mg} / \mathrm{L}$, soluble TP $=14.30 \pm 0.11 \mathrm{mg} / \mathrm{L}, \mathrm{pH}=6.91 \pm 0.01$.

\section{Alkyl polyglucoside}

The surfactant alkyl polyglucoside (APG0810), which was a faint yellow thick fluid (solid content $\geq 50 \%$ ), was purchased from Shanghai Fine Chemical CO., LTD and was used with no further purification. Thus, APG concentration in this paper refers to the concentration of the fluid. Its carbon content was $34.9 \pm 0.3 \%$.

Critical micelle concentration (CMC) is an important characteristic of a surfactant, and it is defined as the concentration of surfactants above which micelles form, and all additional surfactants added to the system form micelles (IUPAC, 1997). Before reaching the CMC, the surface tension changes strongly with the concentration of the surfactant. After reaching the $\mathrm{CMC}$, the surface tension remains relatively constant, or it changes at a slower rate.

The surface tensions of the surfactant aqueous solution and sludge solution were measured and are shown in Figure 1. The CMC of the APG aqueous solution was about 1.5 $\mathrm{g} / \mathrm{L}$, which corresponds with the data provided by the manufacturer, while the $\mathrm{CMC}$ of the APG sludge solution was approximately $3.0 \mathrm{~g} / \mathrm{L}$. Figure 1 also indicates that $\mathrm{NaOH}$ treatment nearly had no effect on the surface tension of the sludge solution.

\section{Methods}

\section{Low-temperature thermo-alkaline pretreatment with APG}

The pretreatment tests were conducted in $150 \mathrm{~mL}$ conical flasks with covers (to avoid water loss by evaporation) fed with $100 \mathrm{~mL}$ of sludge solution. Different volumes of 1 $\mathrm{mol} / \mathrm{L} \mathrm{NaOH}$ and $100 \mathrm{~g} / \mathrm{L}$ APG solution were added to adjust the $\mathrm{pH}$ and APG concentration, respectively. The volume of $\mathrm{NaOH}$ added for reaching a set $\mathrm{pH}$ was determined by a preliminary experiment, whose results are shown in Table 1 .

Table 1. The relationship between $\mathrm{pH}$ and volumes of $\mathrm{NaOH}$

\begin{tabular}{c|c|c|c|c}
\hline Volume of $\mathrm{NaOH}(\mathrm{mL} / 100 \mathrm{~mL})$ & 0.0 & 0.6 & 1.4 & 2.0 \\
$\mathrm{pH}$ & 7 & 10 & 11 & 12 \\
\hline
\end{tabular}

All flasks were maintained in a digital thermostat water bath oscillator, and the solution temperatures were detected by a thermometer. The timer was started as soon as the temperature reached the desired value. Each test was repeated twice.

After completion, samples were centrifuged at $8000 \mathrm{rpm}(3785 \times \mathrm{g})$ for $15 \mathrm{~min}$, the supernatant was filtered by a $0.45 \mu \mathrm{m}$ microporous membrane, and the soluble total organic carbon and soluble total phosphorus were analyzed. In the present study, mixed$\mathrm{STOC}=$ the data from the experimental analysis which included organic carbon both from sludge and APG, and STOC = mixed-STOC - APG $\times 349(1 \mathrm{~g} \mathrm{APG}=349 \mathrm{mg}$ TOC, which can be deduced from section 2.1.3), which included the TOC dissolved just from sludge. 


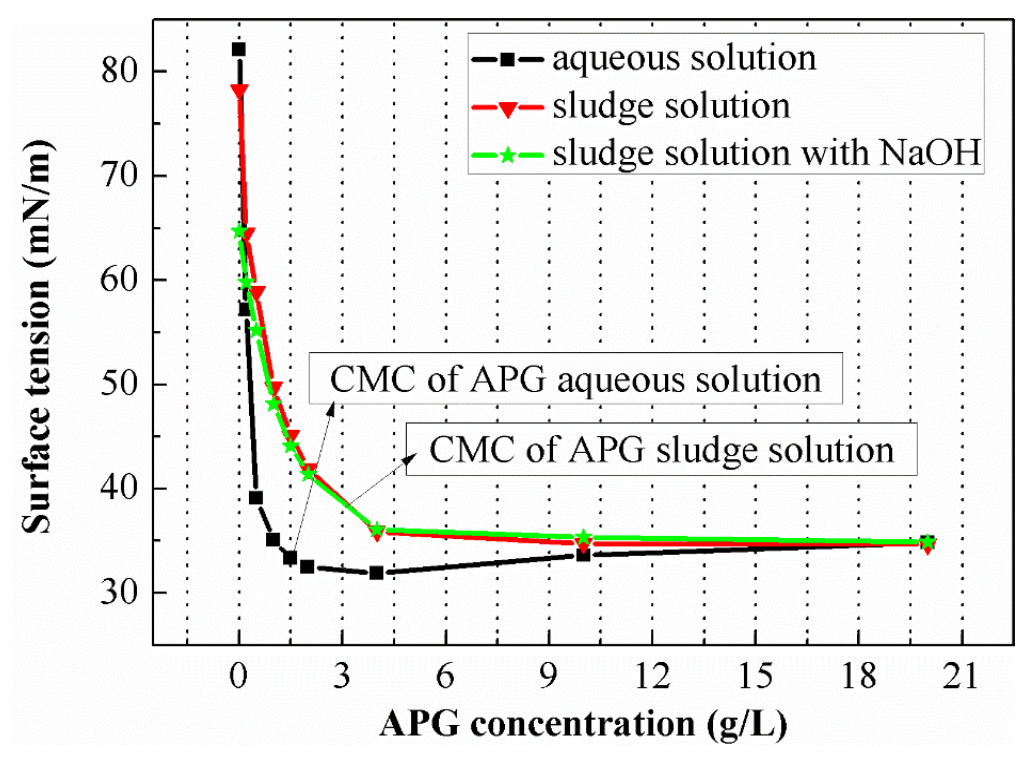

Figure 1. Surface tension of different APG concentrations

STOC represents the effect of the pretreatment. Soluble TP indicates the disintegration of the microbial cells due to those in the WWTPs, polyphosphate accumulation organisms (PAOs) are able to store phosphate as intracellular polyphosphate, leading to P removal via PAO cells in WAS (Oehmen et al., 2007). As a result, soluble TP comes almost entirely from the cellular interior, having dissolved when cells were destroyed.

\section{Orthogonal experiment design}

For the pretreatment tests, sludge was mainly affected by temperature, time, $\mathrm{pH}$, and APG concentration. It was assumed that the four factors had significant influences on pretreatment. The results described herein are from an orthogonal experiment, which was designed for evaluating such experimental factors. Each factor includes three levels, as follows. Temperature: 40,60 , and $80^{\circ} \mathrm{C}$; time: 30,60 , and $90 \mathrm{~min}$; $\mathrm{pH}$ : 7, 10 , and 12 (neutral, alkaline, and strongly alkaline); and APG: 1.5, 3, and $4.5 \mathrm{~g} / \mathrm{L}$ (below $\mathrm{CMC}, \mathrm{CMC}$, and above CMC). Since there were four experimental factors and three levels for each factor, the orthogonal matrix denoted as $\mathrm{L}_{9}\left(3^{4}\right)$ was chosen as the experimental scheme to arrange the tests. Each test was repeated two times, and SPSS software was used for the experiment design and statistical analysis.

\section{Anaerobic digestion tests}

The experiments were conducted using conical flasks in duplicate with a working volume of $500 \mathrm{~mL}$. The bottles contained a magnet rotor (for stirring automatically once a day) and were filled with $200 \mathrm{~mL}$ inocula and $300 \mathrm{~mL}$ pretreated sludge. All pretreatments were under the conditions of $\mathrm{pH}=11$, temperature $=60{ }^{\circ} \mathrm{C}$, time $=60$ $\min , \mathrm{APG}=0,1.5,3.0$, and $5.0 \mathrm{~g} / \mathrm{L}$ (preliminary experiments had proved that when pretreating at APG $>5 \mathrm{~g} / \mathrm{L}$, there is no gas produced in the AD system). The bottles of APG were named T0, T1.5, T3.0, and T5.0, respectively. For comparison, a blank test was run in a flask filled with $200 \mathrm{~mL}$ inocula and $300 \mathrm{~mL}$ raw sludge solution. 
All flasks were incubated at $35^{\circ} \mathrm{C}$ in an electrically heated thermostatic water bath for 35 days until gas was no longer produced. The gas was collected by aluminum foil gas-collecting bags, and gas volume was measured using a syringe. Moreover, the biogas composition was analyzed using gas chromatography (GC). Each test was repeated twice.

\section{Analysis methods}

The analyses of sludge moisture content, TS, VS, COD, TP, and $\mathrm{pH}$ were conducted according to standard methods (APHA, 2005). The surface tension was determined by pulling escape using a JZ-200A automatic interface tensiometer. By using a Shimadzu TOC-Vcph/cpn instrument, TOC was detected by catalytic oxidation nondispersive infrared analysis. The methane was analyzed by a gas chromatograph (Agilent, 6890N) equipped with a flame ionization detector (FID) and a $30 \mathrm{~m} \times 0.32 \mathrm{~mm}$ capillary column (HP-5). The temperature of the injector, detector, and column were kept at $100{ }^{\circ} \mathrm{C}$, $180^{\circ} \mathrm{C}$, and $80^{\circ} \mathrm{C}$, respectively. Helium was used as the carrier gas at a flow rate of $30 \mathrm{~mL} / \mathrm{min}$. Three parallel samples were used for each analysis.

\section{Data calculation formula}

The energy efficiency from the single factor experiments was calculated as in Equation 1.

$$
\text { energy efficiency }=\frac{c \times v}{m \times(T-20) \times c}
$$

where $\mathrm{c}$ is the average concentration value when time $\geq 30 \mathrm{~min}, \mathrm{v}$ is the volume, $\mathrm{m}$ is the mass, $\mathrm{T}$ is the desired temperature, 20 is the room temperature, and $\mathrm{C}$ is the specific heat capacity of water $\left(4.2 \mathrm{~kJ} /{ }^{\circ} \mathrm{C} \cdot \mathrm{kg}\right)$. The unit for energy efficiency is $\mathrm{mg} / \mathrm{kJ}$, which refers to the dissolved quantity of sludge per kJ energy consumed. The heat loss that occurs during the constant temperature process was ignored because of its small value and the difficulties in its calculation.

\section{Results and discussion}

\section{Orthogonal experiment}

The results of the orthogonal experiment for estimating the effects of temperature, time, $\mathrm{pH}$, and APG concentration on the pretreatment of sludge are summarized in Table 2. The F-value shown in Table 2 indicates that the order of the effects of factors on STOC is $\mathrm{pH}>$ temperature $>$ APG concentration $>$ time. For soluble TP, the order of $\mathrm{pH}$ and temperature was the same, but the order of the other two factors (APG concentration and time) was opposite. This distinction indicates that the dissolution of organics was not caused solely by cell disintegration, but was also related to the dissolution of EPSs.

However, dissolution of EPSs contributes to the destruction of cells, and, as a result, the effects of the factors on STOC and soluble TP have a lot in common. As shown in Figure 2, $\mathrm{pH}$ (the most important factor) and temperature (the second most important factor) have similar effects, agreeing with the previous literature (Kim et al., 2015) that an increase of $\mathrm{pH}$ and temperature both enhance the dissolution of organics and 
phosphorus from sludge. Taking into consideration the effects of $\mathrm{pH}$ and temperature on anaerobic digestion (Zhao et al., 2015a) and the energy consumption of the pretreatment, the final $\mathrm{pH}$ of the pretreatment was adjusted to 11 for both pretreatment efficiency and the reducing effect of alkalinity on $\mathrm{AD}$, but the temperature needed some additional experiments.

Table 2. Tests of between-subject effects

\begin{tabular}{|c|c|c|c|c|}
\hline \multirow[t]{2}{*}{ Source } & \multicolumn{2}{|c|}{$\begin{array}{c}\text { Dependent variable: STOC } \\
\text { R Squared }=.996 \\
\text { (Adjusted R Squared }=.992 \text { ) }\end{array}$} & \multicolumn{2}{|c|}{$\begin{array}{c}\text { Dependent variable: soluble TP } \\
\text { R Squared = .999 } \\
\text { (Adjusted R Squared }=.997 \text { ) }\end{array}$} \\
\hline & $\mathbf{F}$ & Sig. & $\mathbf{F}$ & Sig. \\
\hline Corrected Model & 260.748 & .000 & 785.335 & .000 \\
\hline Intercept & 11235.690 & .000 & 17368.888 & .000 \\
\hline Temp & 186.670 & .000 & 199.503 & .000 \\
\hline Time & 3.603 & .071 & 25.473 & .000 \\
\hline APG & 25.808 & .000 & 7.907 & .010 \\
\hline $\mathrm{pH}$ & 826.909 & .000 & 2908.456 & .000 \\
\hline
\end{tabular}
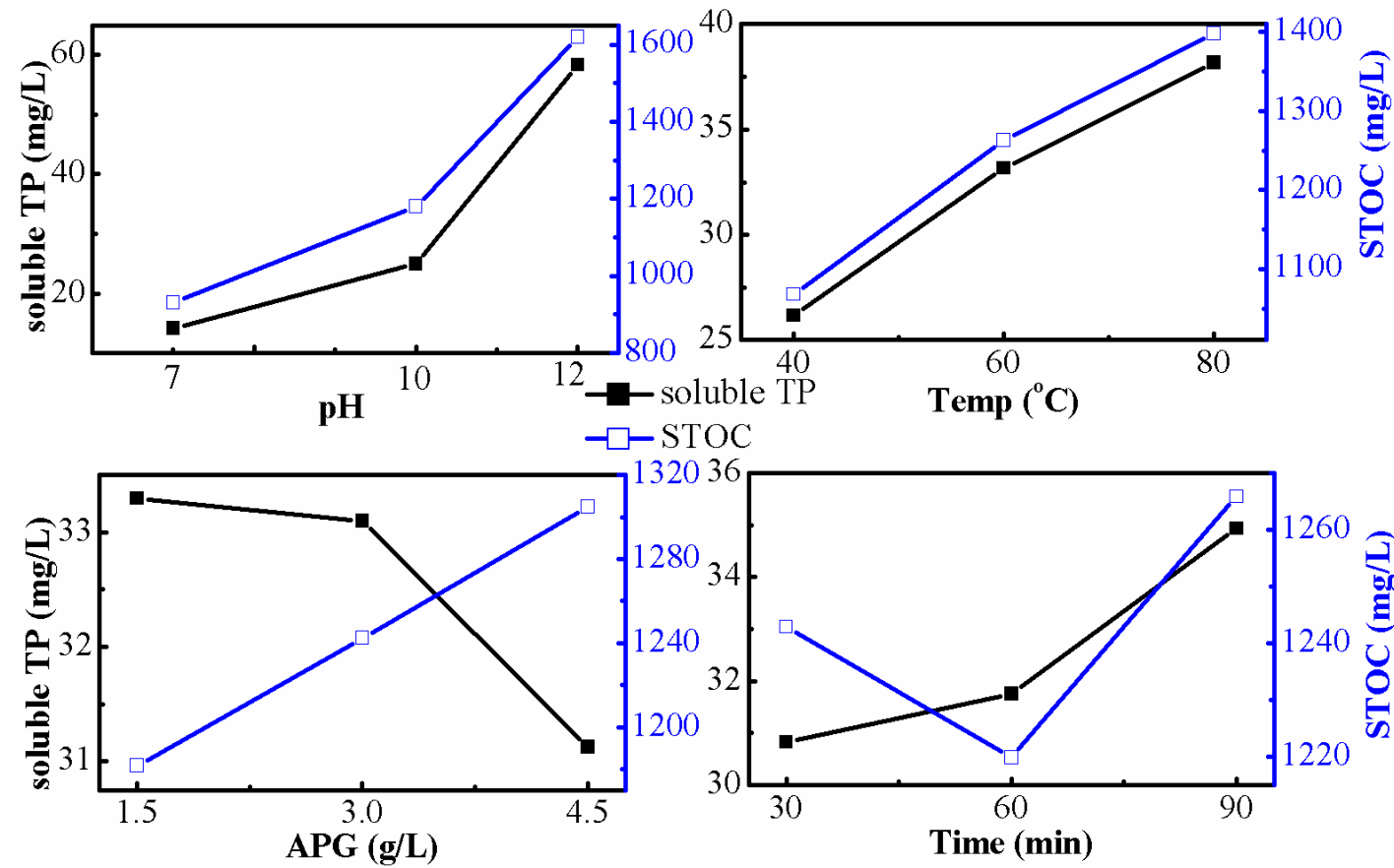

$\square-$ STOC

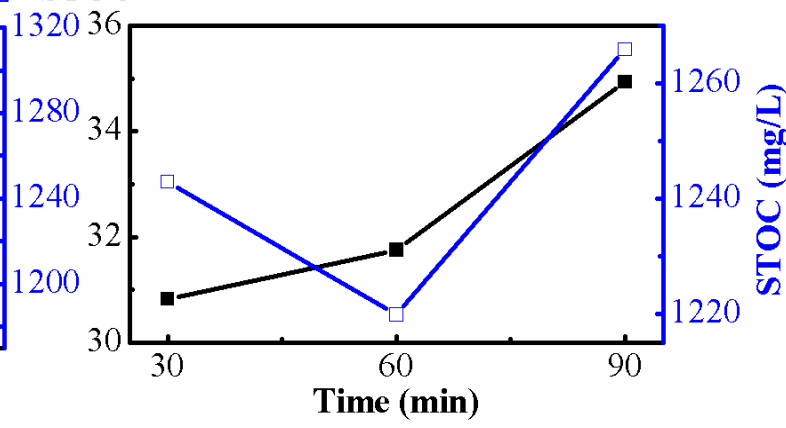

Figure 2. Level effects of each factor on STOC and soluble TP

Figure 2 also shows that for STOC and soluble TP, the least significant factors (time of STOC, APG concentration of soluble TP) have abnormal data, which could be explained by that time and APG concentration were easily affected by the other factors. The orthogonal design has two fundamental limitations: one is that it considers only first-order effects, and the other is that it does not account for the interaction among factors (Zeng et al., 2004). As a result, single factor experiments were required for demonstrating the effects of those two factors. 


\section{Single factor experiments}

\section{Effect of time and determination of appropriate temperature}

The effect of time at various temperatures is shown in Figure $3 a$ for the conditions: $\mathrm{pH}=11 ; \mathrm{APG}=5 \mathrm{~g} / \mathrm{L}$; and temperature $=40^{\circ} \mathrm{C}, 60^{\circ} \mathrm{C}$, and $80^{\circ} \mathrm{C}$. Once alkali and APG were added to the sludge solution, organic matter and phosphorus dissolved in the water rapidly until $30 \mathrm{~min}$ had elapsed, then the dissolving speed slowed down considerably. Referring to the literature (Kim et al., 2013; Ruffino et al., 2016), 60 min was chosen as a pretreatment time to ensure that the pretreatment was comparatively complete.

It is shown in Figure $3 a$ that temperature enhanced the dissolution of organics and phosphorus in the sludge, which is consistent with the result of the orthogonal experiment. However, in Figure 3b, the energy efficiency decreased as the temperature increased, which negates the notion that the hotter the better. Although the dissolved quantity of sludge at $80^{\circ} \mathrm{C}$ was higher than that at $60{ }^{\circ} \mathrm{C}$, the amount of energy consumed at $80^{\circ} \mathrm{C}$ was higher, or the energy efficiency was lower at $80{ }^{\circ} \mathrm{C}$. Besides, it shows that the energy efficiency at $40{ }^{\circ} \mathrm{C}$ was the highest, but the dissolved quantity was compromised (the lowest). Thus, to obtain both the optimal dissolved quantity and energy efficiency, $60{ }^{\circ} \mathrm{C}$ was selected as the optimal temperature.
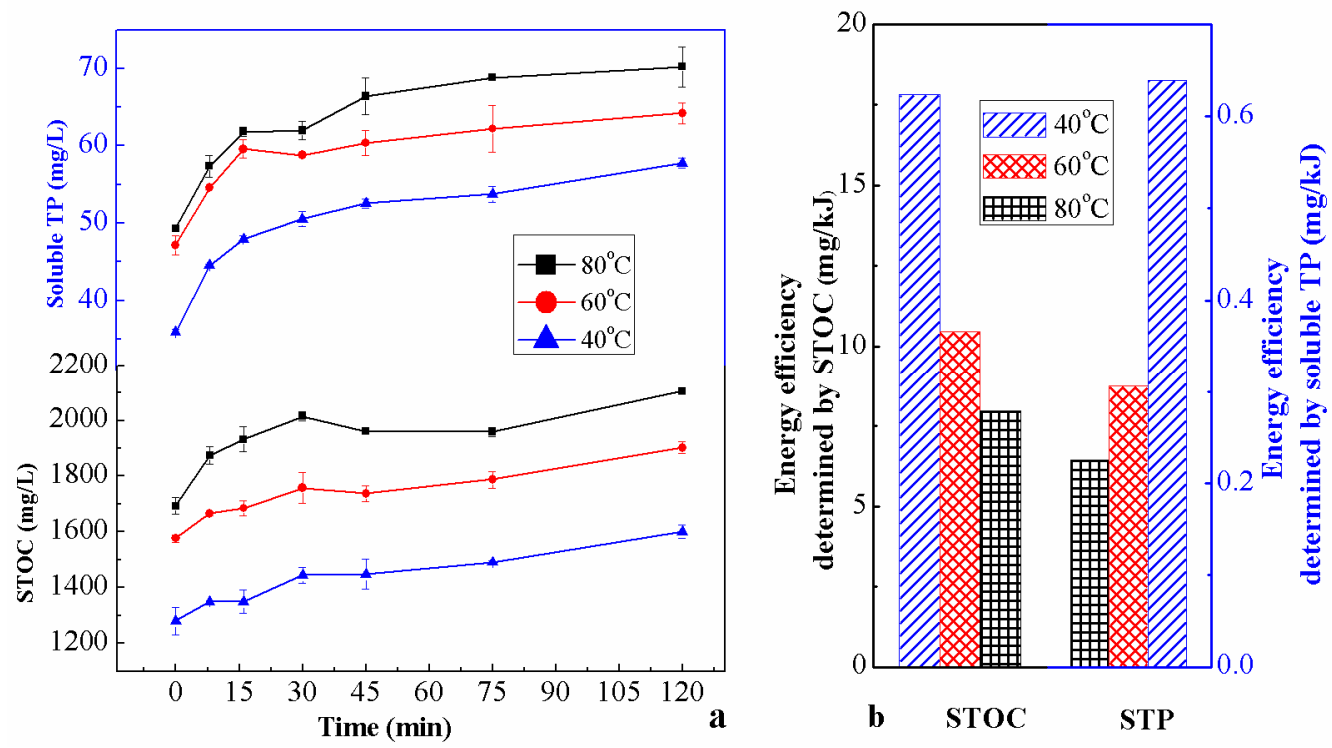

Figure 3. Effects of time on pretreatment

\section{Effect of APG concentration}

The effect of APG is shown in Figure 4 for the conditions of $\mathrm{pH}=11$, temperature $=60{ }^{\circ} \mathrm{C}$, and time $=60 \mathrm{~min}$. The mixed-TOC (TOC from both sludge and APG) had a good linear relationship with APG (Table 3), but there is a discontinuity when $\mathrm{APG}=18 \mathrm{~g} / \mathrm{L}$ (Fig. 4a). The trend of STOC is from rising to declining, which could be explained as follows: Setting APG as $\mathrm{x}$ and mixed-STOC as $\mathrm{y}$, then $\mathrm{y}=\mathrm{k}$ $\mathrm{x}+\mathrm{b}$, and setting STOC as $\mathrm{y}^{\prime}$, then $\mathrm{y}^{\prime}=(\mathrm{k}-349) \mathrm{x}+\mathrm{b}$. It is easy to conclude from the equation that the slope coefficient of $y^{\prime}(k-349)$ changed due to the change of the coefficient of $y$ ( $\mathrm{k}$, from 446.1 to 275.4 ) at the point where $\mathrm{APG}=18 \mathrm{~g} / \mathrm{L}$. Also, it is 
clear from the figure that at the point where $A P G=18 \mathrm{~g} / \mathrm{L}$, the efficiency of APG decreased slowly and then rapidly.

Table 3. Linear fitting equation of $A P G(x)$ and mixed-STOC (y)

\begin{tabular}{c|c|c}
\hline APG concentration $(\mathbf{m g} / \mathbf{L})$ & Linear equation & $\mathbf{R}^{\mathbf{2}}$ \\
\hline$[0,18]$ & $\mathrm{y}=446.1 \mathrm{x}+970.7$ & 0.999 \\
{$[18,30]$} & $\mathrm{y}=275.4 \mathrm{x}+4017$ & 0.998 \\
\hline
\end{tabular}
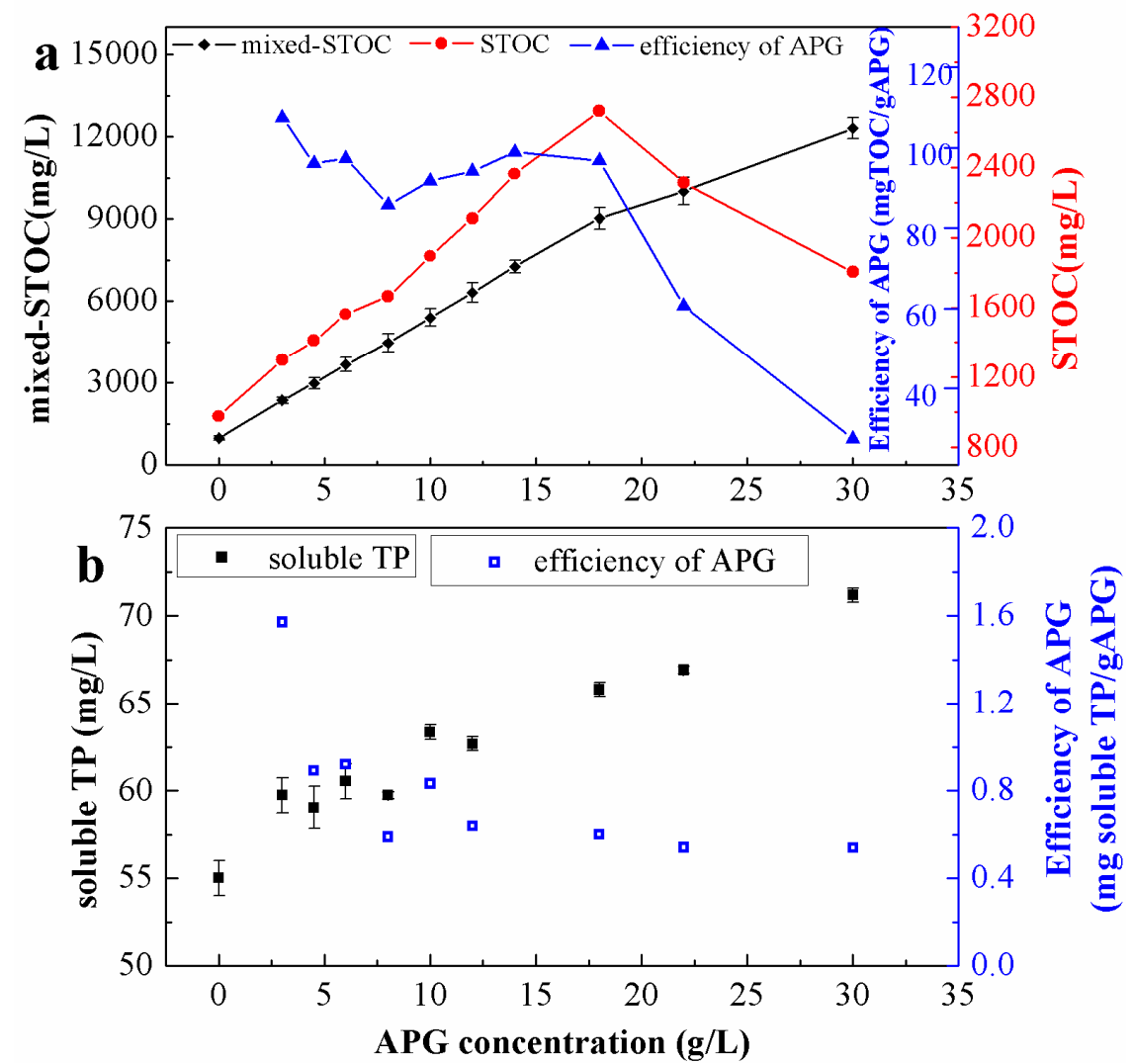

Figure 4. Effects of APG concentration on STOC (a) and soluble TP (b). In (a), the efficiency of $A P G=\left(S T O C-S T O C_{0}\right) / A P G$, where the $S T O C_{0}$ is $S T O C$ with $A P G=0 \mathrm{mg} / \mathrm{L}$. In (b), the efficiency of $A P G=\left(\right.$ soluble $T P-$ soluble $\left.T P_{0}\right) / A P G$, where the soluble $T P_{0}$ is soluble $T P$ with $A P G=0 \mathrm{~g} / \mathrm{L}$

In Figure $4 a$, when APG $<18 \mathrm{~g} / \mathrm{L}$, the higher the APG concentration, the more organics dissolved from the sludge. However, when APG concentration is over $18 \mathrm{~g} / \mathrm{L}$, STOC inversely decreases as APG increases. This could be explained as follows: When the concentration of a surfactant is above its CMC, micelles transform from spherical to rod-like. The rod-like micelles would even become associated if continuously adding the surfactant (Rakshit, 2008). In other words, a concentration above the CMC induces the formation of bigger micelles. When the micelles are large enough to be blocked by a microporous membrane, the organics in these micelles may not appear in the dissolved form. In this solution system, $18 \mathrm{~g} / \mathrm{L}$ was the critical concentration, at which there were micelles blocked by a $0.45 \mu \mathrm{m}$ microporous membrane. 
In Figure 4b, soluble TP increases with increasing APG dosage, which indicates that more APG led to more cell disintegration. Phosphorus was not contained in micelles, so big micelles blocked by the microporous membrane did not affect it; therefore, there was no discontinuity insoluble TP.

Similar to other surfactants, some APG molecules formed micelles when the concentration was above its CMC. Thus, the quantity of effective APG molecules did not have a linear increase with its concentration, resulting in the decreasing efficiency of APG in both Figure $4 a$ and $b$.

\section{Anaerobic digestion}

\section{Gas production}

The biogas production from $\mathrm{AD}$ is shown in Figure 5 as a function of fermentation time (on the x-axis) and cumulative gas volume (on they-axis). Comparing the blank with T0 shows that after the low-temperature thermo-alkaline pretreatment without APG, there was higher biogas production efficiency of T0, which is consistent with the literature (Li et al., 2016). However, pretreatment with different dosages of APG had a significant effect on the gas production.

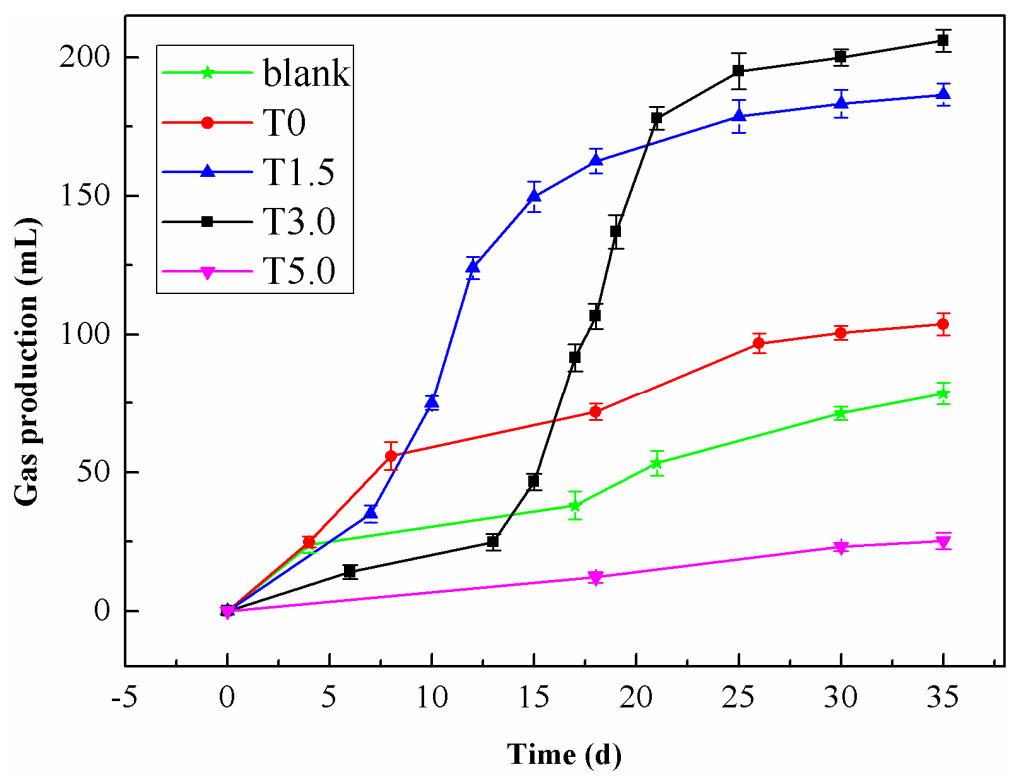

Figure 5. Total volume of biogas in $A D$

Comparing T0 with T1.5, it was found that adding APG to the pretreatment had a greater impact on $\mathrm{AD}$ than adding solely alkali. Moreover, the gas production of T1.5 increased rapidly about 7 days later, which means that the microorganisms in T1.5 had an adaptive phase of 7 days.

In comparison with T1.5, it was observed that the gas production rate of T3.0 started rising rapidly on the 13th day. The longer adaptive phase defines the inhibiting effect of APG on the microorganisms in the anaerobic system. When the APG concentration is less than the $\mathrm{CMC}$, the adaptive phase increases with increasing APG dosage.

Assuming that there was no wastage of APG during the process of pretreatment, APG concentration in the fermentation broth was $0.9 \mathrm{~g} / \mathrm{L}$ for T1.5, $1.8 \mathrm{~g} / \mathrm{L}$ for T3.0, and 
$3.0 \mathrm{~g} / \mathrm{L}$ for T5.0 (APG was diluted 5/3 times by inocula). It is shown in Figure 5 that T5.0 produced a small amount of biogas, which suggests that the aerogen can hardly adapt to the APG concentration at CMC (the CMC of the APG sludge solution was approximately $3.0 \mathrm{~g} / \mathrm{L}$, section 2.1 .3 ). Considering the result of preliminary experiments indicating that there were no bubbles in the fermentation liquor when pretreating at $\mathrm{APG}>5.0 \mathrm{~g} / \mathrm{L}$, it is the APG micelles that have a negative impact of activity on the aerogen. However, in the study by Xia and Onyukse (2000), they found that it was the surfactant monomer, not the micelle, that went through the cell membrane to damage the cell. Therefore, as they stated, "micelles may act as a depot to continuously replace aqueous surfactant monomers taken up by the membrane."

\section{Property analysis of fermentation liquor and biogas}

The compositions of the liquor and biogas during fermentation are shown in Figure 6. The sludge solutions of T0, T1.5, T3.0, and T5.0 pretreated by the lowtemperature thermo-alkaline method (initial $\mathrm{pH}=11$ ) were mixed with inocula. All $\mathrm{pH}$ was between 8.8 and 8.9, as shown in Figure $6 a$, and all $\mathrm{pH}$ values were significantly reduced after 35 days. The $\mathrm{AD}$ of the organic material basically follows hydrolysis, acidogenesis, acetogenesis, and methanogenesis (Appels et al., 2008). It could be deduced that the main cause of the $\mathrm{pH}$ reduction was acidogenesis and acetogenesis.

It is known that methanogens are extremely sensitive to $\mathrm{pH}$, with an optimum between 6.5 and 7.2 (Appels et al., 2008), and the optimal $\mathrm{pH}$ of hydrolysis and acidogenesis is between 5.5 and 6.5 (Ward et al., 2008). As shown in Figure 6a, the pH values of the blank, T0, T1.5, and T3.0 after AD were between 6.5 and 7.2, which may indicate that the maximal activity strain in the fermentation reactor was a methanogen. However, Figure $6 b$ also shows that it is only in T1.5 and T3.0 that there was a relatively large $\mathrm{CH}_{4}$ volume fraction. Only $1.66 \mathrm{vol} \%$ methane in the blank was produced, which is because the poor efficiency of hydrolysis made acidogenesis difficult (the $\mathrm{pH}$ changed just from 6.97 to 6.80), so of course acetogenesis and methanogenesis were limited. In $\mathrm{T} 0$, the pretreatment facilitated hydrolysis, so acidogenesis and acetogenesis made the $\mathrm{pH}$ drop sharply from 8.80 to 7.13 . The low methane yield may be caused by the limitation of low organic substrate concentration, since the ratio of VS to TS of sludge used in this study was just $51.32 \pm 0.10 \%$ (shown in section2.1.1). Adding APG to the pretreatments more effectively promoted the dissolution of organics in the sludge, and APG could even act as an organic substrate, thus leading to the relatively large amount of $\mathrm{CH}_{4}$ in $\mathrm{T} 1.5$ and T3.0, compared to that in T0.

Meanwhile, the $\mathrm{pH}$ of T5.0 was at the optimum for hydrolysis and acidogenesis (5.56.5, Fig. 6a), and there was no methane detected (Fig. 6b), both of which suggest that the activity of the methanogens in the T5.0 anaerobic system was extremely low. This conclusion could be also deduced by its STOC reduction rate (Fig. 6c).

The STOC reduction rate is unequal to the carbon utilization rate of methanogens, because hydrolysis, acidogenesis, acetogenesis, and methanogenesis simultaneously occur in a mixed anaerobic system. That is to say, when soluble carbon was being converted into $\mathrm{CH}_{4}$, and $\mathrm{CO}_{2}$ volatilizing from the liquor, the carbon in the suspended solids was being dissolved into the water by hydrolysis and acidogenesis. However, it is only soluble carbon that methanogens can utilize, so the STOC reduction rate is, to some extent, equal to the activity of methanogens. Figure $6 c$ shows that T5.0 had a STOC reduction rate far below that of the other tests, showing its low methanogen 
activity. Taking the conclusion of section 3.3.1 into consideration, APGs have more of a negative impact of activity on methanogens than on other strains in the AD system. The literature (Luo et al., 2015) reports that there was far more Firmicutes in WAS anaerobic reactors with APG than without APG (42.6\% vs. 9.8\%), from which it could be deduced that a firm cell wall can help to protect the bacteria from the toxic effect of APG. Methanogens belong to Archaea, whose cell wall is comparatively weak, so APG monomers easily go through cell membranes and cause them damage.
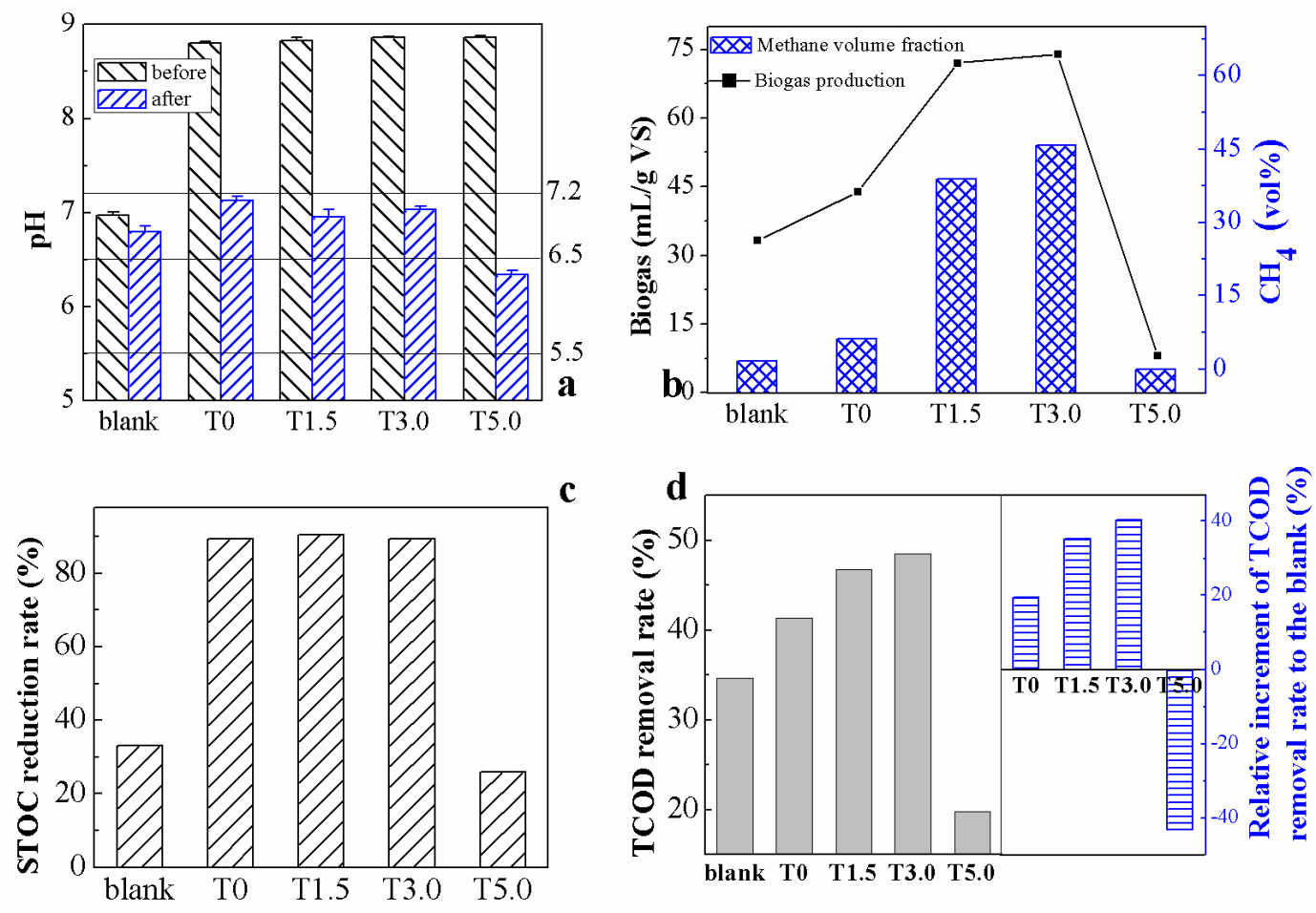

Figure 6. Property analysis of fermentation liquor and biogas. (a) The change of $p H$ before and after $A D$. (b) Biogas yield and volume fraction of $\mathrm{CH}_{4}$. In (c), STOC reduction rate $=\left(S T O C_{b}-\right.$ $\left.S T O C_{a}\right) / S T O C_{b}$, where $S T O C_{b}$ is soluble total organic carbon in the fermentation broth before fermenting, and $S T O C_{a}$ is after fermenting. In (d), TCOD removal rate $=\left(T C O D_{b}-\right.$

$\left.T C O D_{a}\right) / T C O D_{b}$, where $T C O D_{b}$ is total chemical oxygen demand in the fermentation broth before fermenting, and TCOD $a$ is after fermenting. The relative increase of the TCOD removal

rate, compared to the blank $=T C O D$ removal rate of $(T \alpha-$ blank $) /$ blank $\times 100 \%$, which quantifies the comparison between TCOD removed by AD with pretreatment (T0, T1.5, T3.0, T5.0) and without pretreatment (blank)

The rate of TCOD removal can be considered to represent the organics utilization rate in the AD system. It is observed from Figure $6 d$ that the APG dosage increased the organics utilization rate when the APG concentration was under the CMC. However, when the APG was plentiful enough to generate abundant micelles (APG concentration $\geq \mathrm{CMC}$ ), the micelles sharply lowered the activity of the methanogens to inhibit methanogenesis, so the organics utilization rate of T5.0 decreased obviously. This is why Zhao et al. (2015b) and Luo et al. (2015) added APG to anaerobic fermentation systems to inhibit methanogenesis in order to accumulate short-chain fatty acids (SCFAs). 
The relative increase of the TCOD removal rate compared to the blank (Fig. $6 d$ ) suggests that pretreatment does improve the efficiency of AD. The relative increase of T0 was $19.37 \%$, and that of T3.0 was $40.30 \%$. It was easy to calculate that 40.30 is $108.07 \%$ greater than 19.37 , significantly demonstrating that $3.0 \mathrm{~g} / \mathrm{L}$ is a reasonable selection for the optimal APG dosage. This is due to the fact that, during pretreatment, APG at the CMC promotes dissolution of EPSs, which accelerates hydrolysis. Further, when fermenting, APG is diluted to below CMC, so its toxicity to methanogens is reduced.

In addition, the methane volume fraction of T3.0 was $45.84 \%$ (Fig. $6 b$ ), which is lower than normal biogas $\left(\mathrm{CH}_{4}\right.$ volume fraction of digestion biogas was $53-70 \%$; Appels et al., 2008). In comparison with the blank (1.66\%) and T0 (6.17\%), T3.0 nearly realized sludge recycling.

Although there was an adaption phase in the AD system because of APG, this disadvantage could be overcome by additional high-efficiency gas production studies in a continuous fermentation system (not in a sequencing batch reactor, as in the present experiment). Further, although the methane content was low because of the lack of organic substrate, other degradable organic waste, such as food waste, could be used to increase the organic substrate concentration. However, these suppositions need to be confirmed by more experiments.

\section{Conclusion}

A low-temperature thermo-alkaline pretreatment with APG for WAS with low organic content could greatly improve the sludge utilization in AD systems. More APG led to more dissolution of organic matter during the pretreatment, but in fermentation, APG above the CMC severely inhibited methanogenesis. As a result, $3.0 \mathrm{~g} / \mathrm{L}$ was chosen as the optimal APG dosage. Under optimum conditions, pretreated sludge was fermented anaerobically at mesophilic temperatures to obtain the best biogas production, $\mathrm{CH}_{4}$ volume fraction, and organics utilization rate. Although there was an adaptive phase of 13 days and the methane content was low, additional experiments could be conducted to find solutions that overcome these disadvantages.

Acknowledgements. This research was financially supported by the project of National Natural Science Foundation of China (NSFC) (Nos.51179068, 51521006).

\section{REFERENCES}

[1] APHA (2005): Standard Methods for the Examination of Water and Wastewater. 21 st Ed. - Public Health Association, Washington, DC.

[2] Appels, L., Baeyens, J. et al. (2008): Principles and potential of the anaerobic digestion of waste-activated sludge. - Progress in Energy and Combustion Science 34(6): 755-781.

[3] Appels, L., Degrève, J. et al. (2010): Influence of low temperature thermal pre-treatment on sludge solubilisation, heavy metal release and anaerobic digestion. - Bioresource Technology 101(15): 5743-5748.

[4] Bougrier, C., Delgenès, J. P. et al. (2008): Effects of thermal treatments on five different waste activated sludge samples solubilisation, physical properties and anaerobic digestion. - Chemical Engineering Journal 139(2): 236-244. 
[5] Carrere, H., Dumas, C. et al. (2010): Pretreatment methods to improve sludge anaerobic degradability: a review. - J Hazard Mater 183(1-3): 1-15.

[6] Du, J., Qian, Y. et al. (2019): Hydrothermal and alkaline thermal pretreatment at mild temperature in solid state for physicochemical properties and biogas production from anaerobic digestion of rice straw. - Renewable Energy 139: 261-267.

[7] Ennouri, H., Miladi, B. et al. (2016): Effect of thermal pretreatment on the biogas production and microbial communities balance during anaerobic digestion of urban and industrial waste activated sludge. - Bioresour Technol 214: 184-191.

[8] Fernández-Marchante, C. M., Asensio, Y., León, L. F. ... Lobato, J., Rodrigo, M. A. (2018): Thermally-treated algal suspensions as fuel for microbial fuel cells. - Journal of Electroanalytical Chemistry 814: 77-82.

[9] Geetha, D., Tyagi, R. (2012): Alkyl Poly Glucosides (APGs) Surfactants and their properties: a review. - Tenside Surfactants Detergents 49(5): 417-427.

[10] Guan, R., Yuan, X. et al. (2017): Functionality of surfactants in waste-activated sludge treatment: a review. - Sci Total Environ 609: 1433-1442.

[11] Hale, R. C., La Guardia, M. J. et al. (2012): Polybrominated diphenyl ethers in U.S. sewage sludges and biosolids: temporal and geographical trends and uptake by corn following land application. - Environ Sci Technol 46(4): 2055-2063.

[12] IUPAC (1997): Compendium of Chemical Terminology (Compiled by A. D. McNaught and A. Wilkinson). - Blackwell Scientific Publications, Oxford.

[13] Jae, M., Sun, K. et al. (2018): Enhancement of methane production in anaerobic digestion of sewage sludge by thermal hydrolysis pretreatment. - Bioresource Technology 259: 207-213.

[14] Kelessidis, A., Stasinakis, A. S. (2012): Comparative study of the methods used for treatment and final disposal of sewage sludge in European countries. - Waste Manag 32(6): 1186-1195.

[15] Kim, J., Yu, Y. et al. (2013): Thermo-alkaline pretreatment of waste activated sludge at low-temperatures: effects on sludge disintegration, methane production, and methanogen community structure. - Bioresour Technol 144: 194-201.

[16] Kim, M., Han, D. W. et al. (2015): Selective release of phosphorus and nitrogen from waste activated sludge with combined thermal and alkali treatment. - Bioresour Technol 190: 522-528.

[17] Li, C., Zhang, G. et al. (2016): Alkaline thermal pretreatment at mild temperatures for biogas production from anaerobic digestion of antibiotic mycelial residue. - Bioresour Technol 208: 49-57.

[18] Liu, R., Yu, X. et al. (2019): New insights into the effect of thermal treatment on sludge dewaterability. - Science of the Total Environment 656: 1082-1090.

[19] Luo, J., Feng, L. et al. (2015): Alkyl polyglucose enhancing propionic acid enriched short-chain fatty acids production during anaerobic treatment of waste activated sludge and mechanisms. - Water Res 73: 332-341.

[20] Mendez, L., Mahdy, A. et al. (2013): Enhancing methane production of Chlorella vulgaris via thermochemical pretreatments. - Bioresour Technol 149: 136-141.

[21] Murakami, T., Suzuki, Y. et al. (2009): Combustion characteristics of sewage sludge in an incineration plant for energy recovery. - Fuel Processing Technology 90(6): 778-783.

[22] Nguyen, M. T., Mohd Yasin, N. H. et al. (2014): Enhancement of sludge reduction and methane production by removing extracellular polymeric substances from waste activated sludge. - Chemosphere 117: 552-558.

[23] Oehmen, A., Lemos, P. C. et al. (2007): Advances in enhanced biological phosphorus removal: from micro to macro scale. - Water Res 41(11): 2271-2300.

[24] Rakshit, A. K. (2008): Micelles: a short review. - Journal of the Indian Chemical Society 85(12): 1289-1300. 
[25] Ruffino, B., Campo, G. et al. (2016): Preliminary technical and economic analysis of alkali and low temperature thermo-alkali pretreatments for the anaerobic digestion of waste activated sludge. - Waste and Biomass Valorization 7(4): 667-675.

[26] Sheng, G. P., Yu, H. Q. et al. (2010): Extracellular polymeric substances (EPS) of microbial aggregates in biological wastewater treatment systems: a review. - Biotechnol Adv 28(6): 882-894.

[27] Song, U., Lee, E. J. (2010): Environmental and economical assessment of sewage sludge compost application on soil and plants in a landfill. - Resources, Conservation and Recycling 54(12): 1109-1116.

[28] Wang, L.-F., He, D.-Q. et al. (2014): Characterization of dewatering process of activated sludge assisted by cationic surfactants. - Biochemical Engineering Journal 91: 174-178.

[29] Ward, A. J., Hobbs, P. J. et al. (2008): Optimisation of the anaerobic digestion of agricultural resources. - Bioresour Technol 99(17): 7928-7940.

[30] Xia, W. J., Onyuksel, H. (2000): Mechanistic studies on surfactant-induced membrane permeability enhancement. - Pharmaceutical Research 17(5): 612-618.

[31] Yang, G., Zhang, G. et al. (2015): Current state of sludge production, management, treatment and disposal in China. - Water Res 78: 60-73.

[32] Zeng, S. Y., Kang, L. S. et al. (2004): An orthogonal multi-objective evolutionary algorithm for multi-objective optimization problems with constraints. - Evol Comput 12: 77-98.

[33] Zhang, Y., Feng, Y. et al. (2015): Zero-valent iron enhanced methanogenic activity in anaerobic digestion of waste activated sludge after heat and alkali pretreatment. - Waste Management 38: 297-302.

[34] Zhao, J., Yang, Q. et al. (2015a): Effect of initial $\mathrm{pH}$ on short chain fatty acid production during the anaerobic fermentation of membrane bioreactor sludge enhanced by alkyl polyglcoside. - International Biodeterioration \& Biodegradation 104: 283-289.

[35] Zhao, J., Yang, Q. et al. (2015b): Enhanced production of short-chain fatty acid from food waste stimulated by alkyl polyglycosides and its mechanism. - Waste Manag 46: 133-139. 